\title{
Conducting Online Problem-based Learning Tutorials during the COVID-19 Pandemic
}

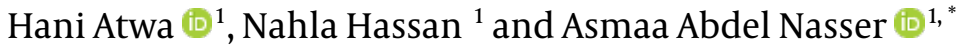 \\ ${ }^{1}$ Faculty of Medicine, Suez Canal University, Ismailia, Egypt \\ "Corresponding author: Medical Education Unit, Ibn Sina National College for Medical Studies, Jeddah, Saudi Arabia. Email: dr.asmaashraf@gmail.com
}

Received 2021 March 08; Accepted 2021 April 26.

Keywords: PBL, Tutorials, Medical Students, COVID-19

\section{Dear editor,}

The COVID-19 pandemic has affected educational systems all over the world, resulting in the shift from traditional problem-based learning (PBL) tutorial classes to virtual PBL online classes, especially in Arab countries. The effect of this suspension was obvious in institutions whose educational systems depend mainly on interactive smallgroup sessions like PBL.

\section{What problem was addressed?}

Educational institutions around the world have suffered from the COVID-19 pandemic due to the suspension of studies. The effect of this suspension was obvious in institutions whose educational systems depend mainly on interactive small-group sessions, like problembased learning (PBL). Undergraduate medical education was among the systems that suffered a lot.

PBL is used to be conducted on campus in small groups of 10 - 13 students who, with the help of a facilitator (tutor), meet to brainstorm around a real-world clinical problem and meet again after a few days to discuss learning issues explored through such brainstorming and solving the problem. The result is that students explore new concepts and deeply acquire new knowledge in an active learning manner (1).

\section{What was tried?}

As PBL is one of the most important small-group learning methods, we were prompted to plan for a quick transformation of face-to-face PBL tutorial sessions into virtual ones once classes were suspended due to the pandemic. Educational problems, tutor guides, and evaluation forms have been reviewed and adapted for online use. Two com- munication channels - WhatsApp (WhatsApp, Inc., Menlo Park, CA, USA) and emails - were employed to communicate with tutors and student groups and to send them the materials, instructions, and updates. Tutors also communicated with their group students through the same channels.

Students were divided into 16 groups of 10 - 13 students. A tutor was assigned for each group, who was assigned as a host in a Zoom ${ }^{\mathrm{TM}}$ (Zoom Video Communications, Inc., San Jose, CA, USA) account, through which the tutorials were conducted. The recording function of $\mathrm{Zoom}^{\mathrm{TM}}$ was set as default to record the sessions for review at a later time by the Medical Education Unit.

The tutorials were conducted on two sessions: (1) brainstorming, and (2) debriefing. The sessions lasted on average for 90 minutes, with a 4-day gap between the individual study and self-learning. Flexibility was considered through allowing the tutors and students to conduct the sessions at their convenient time.

Students' attitude toward virtual PBL was positive. The attendance rate during the PBL virtual sessions was $99 \%$, and almost no internet connection problems were encountered. All the filled electronic PBL evaluation forms were collected through emails.

\section{What lessons were learned?}

During this COVID-19 pandemic, students were still motivated to have online PBL tutorial sessions. They could still work in groups, identify what they want to learn, define their learning issues, find resources, and evaluate their learning progress to meet their goals, all collaboratively and virtually. Tutors and students could still maintain interaction, even in a better manner, due to the absence of 
such constraints as space and reduction of possible anxiety associated with face-to-face discussion in traditional PBL.

\section{Footnotes}

Authors' Contribution: H.A., N.H., and A.A. participated in conceptualizing, designing, and drafting the manuscript.
Conflict of Interests: The authors declared no conflict of interests.

Funding/Support: There was no funding.

\section{References}

1. Yew EHJ, Goh K. Problem-based learning: An overview of its process and impact on learning. Health Prof Educ. 2016;2(2):75-9. doi: 10.1016/j.hpe.2016.01.004. 